\title{
Vínculos religiosos entre estudantes universitários: comparações entre licenciatura e bacharelado ${ }^{1}$
}

\section{Religious connections of university students: comparisons between bachelor's and licentiate's programs}

\author{
Eva Lenita Scheliga* \\ Adriane Knoblauch* \\ Karina Kosicki Bellotti*
}

\begin{abstract}
RESUMO
$\mathrm{O}$ atual contexto de maior visibilidade das manifestações religiosas na esfera pública, e na educação em especial, impeliu-nos a estabelecer relações entre diferentes vínculos religiosos e os itinerários formativos no interior da universidade, com foco na comparação entre bacharelado e licenciatura. Os dados foram coletados por meio de questionário aplicados a uma amostra de 385 estudantes da Universidade Federal do Paraná. Analisamos a declaração de vínculo religioso, a frequência em grupo(s) religioso(s) no ano de 2018 e a filiação religiosa institucional dos discentes. Mais de um terço dos respondentes - $38 \%$ - afirmou possuir algum vínculo religioso, sendo predominantes os elos com as religiões de matriz cristã: a maioria declara pertencer à religião católica, seguidos das religiões evangélicas. Há, também, um expressivo número de estudantes sem filiação religiosa específica, os "sem religião". Dentre os estudantes de bacharelado que se declaram religiosos, a maior parte é católica, seguida dos evangélicos, com proporção
\end{abstract}

1 A pesquisa foi viabilizada por meio da articulação de três projetos individuais de pesquisa, aprovados no Edital Programa Institucional de Bolsas de Iniciação Científica da Universidade Federal do Paraná (PIBIC/UFPR) 2017/2018, resultando no desenvolvimento de planos de trabalho para quatro bolsistas. Três deles trabalharam de forma voluntária e uma recebeu bolsa de pesquisa UFPR-Tesouro Nacional.

* Universidade Federal do Paraná. Curitiba, Paraná, Brasil. E-mail: evascheliga@ufpr. br - http://orcid.org/0000-0002-2270-0636 — E-mail: adrianeknoblauch@gmail.com - https:// orcid.org/0000-0002-8842-4128 — E-mail: karinakbellotti@gmail.com -https://orcid.org/0000$0002-5353-8432$ 
próxima entre evangélicos de missão e pentecostais. Nas licenciaturas, ao contrário, a maioria dos que se declaram religiosos é evangélica, sendo a maior parte vinculada a denominações pentecostais. A frequência religiosa sofre poucas modificações após o ingresso na universidade. Destacamos o fato de os discentes das licenciaturas participarem mais ativamente em suas comunidades de fé em comparação com seus colegas do bacharelado.

Palavras-chave: Religião. Juventude. Bacharelado. Licenciatura.

\begin{abstract}
The current context of higher visibility of religious manifestations in the public sphere, and mainly in the Educational field, compelled us to establish relations between different religious attachments and formative itineraries within the university, focusing the comparison between students of bachelor's and licentiate's programs. The data were collected from a sample of 385 students from Universidade Federal do Paraná [Federal University of Paraná], through a survey. We analyzed the students' declaration of religious links, the attendance to religious group(s) in 2018 and their institutional religious affiliation. More than a third of the respondents $-38 \%$ - claimed to have some type of religious attachment, being predominant the links with Christian religions; the majority declared their adherence to Catholicism, followed by the Evangelical religions. There is, also, an expressive number of students without any religious affiliation, the "non-religious" people. Among the bachelor's degree students who declared to be religious, most of them are Catholics, followed by the Evangelicals, with relatively equal distribution between Evangelicals of Mission and Pentecostals. The students' religious attendance suffers little modification after going to college. We highlight the fact that the licentiate's degree students engage more actively with their faith communities in comparison with their bachelor's degree colleagues.
\end{abstract}

Keywords: Religion. Youth. Bachelor's program. Licentiate's program.

\title{
Introdução
}

Fomentar uma discussão sobre as relações entre diversidade religiosa, juventude e contextos de formação universitária constituiu um dos objetivos gerais da pesquisa "Diversidade religiosa na Universidade Federal do Paraná", que origina este trabalho. Trata-se de um levantamento de dados inédito, realizado entre 2018 e 2019, junto a uma amostra dos discentes de graduação presencial da Universidade Federal do Paraná (UFPR) matriculados em Curitiba. 
A produção de informações sobre a diversidade religiosa em contextos universitários é pertinente por inúmeras razões. Primeiramente porque, através dela, é possível consolidar políticas de combate a intolerâncias e preconceitos, dentre os quais incluem-se os relativos às identidades religiosas. Em segundo lugar, porque podem oferecer subsídios para que docentes e servidores técnicos contemplem a pluralidade religiosa em suas estratégias de ensino, pesquisa e extensão. Por fim, e não menos importante, porque observamos que no caso da educação, as relações com a religião vêm se mostrando tensas, sobretudo nos seguidos embates a respeito da inclusão ou não da disciplina Ensino Religioso, a cada nova aprovação da Lei de Diretrizes e Bases (CUNHA, 2014; CURY, 2004). Mais recentemente, a tensão foi intensificada por ocasião da aprovação dos Planos Municipais, Estaduais e Nacional de Educação, especialmente em função das questões voltadas às relações de gênero e à diversidade.

Constatamos que trata-se de um campo de reflexões ainda em expansão na área de Educação no Brasil, de modo que o artigo também pretende oferecer insights para a consolidação do mesmo eixo de pesquisa. Knoblauch (2017) afirma que entre alunas de Pedagogia de uma universidade do Sul do país, 81\% se dizem religiosas e sua fé orienta e seleciona aprendizados no decorrer do curso, sobretudo em relação às questões de gênero. Pinheiro e Santos (2017) mencionam que mais de $70 \%$ dos estudantes de Educação Física de uma IES privada de Belo Horizonte também se consideram religiosos. Além disso, os estudos de Teixeira e Andrade (2014) e de Dorvillé e Selles (2009), ambos realizados com professores de Biologia do Rio de Janeiro, mostram tensões entre a formação universitária e a vivência religiosa de professores do Ensino Básico, em torno de conteúdos sobre evolução e o criacionismo. Malacarne (2009) também identificou esse tensionamento com professores de Ciências Naturais de uma região do Paraná. Valente (2017), por sua vez, aponta que a religiosidade está presente no cotidiano escolar de forma difusa e orienta práticas pedagógicas selecionando estratégias para o trabalho com a literatura infantil.

O diálogo com esse conjunto de trabalhos (todos com foco em diferentes licenciaturas) nos lançou o desafio de analisar o universo religioso dos estudantes do Ensino Superior, a fim de verificar se havia ou não diferenças de filiações e práticas religiosas entre discentes do bacharelado e da licenciatura. Destacamos que essa pesquisa se propõe a estudar a diversidade religiosa no conjunto de uma universidade, diferenciando-se de outras investigações feitas no âmbito de cursos específicos de instituições de ensino públicas e privadas ${ }^{2}$. A comparação

2 Fora do Brasil, destacamos a pesquisa "The Spiritual Life of College Students", conduzida pelo grupo de pesquisa "Spirituality in Higher Education", da Universidade da Califórnia em Los Angeles (UCLA). O survey foi realizado junto a cerca de 112.000 matriculados em 236 universidades 
entre estudantes de bacharelado e licenciatura de uma mesma universidade nos pareceu promissora para tecer análises, tendo em vista que o exercício de comparação com outras instituições não foi possível, como será destacado na próxima seção.

Reconhecemos, ademais, que a religião está imbricada em outras instâncias sociais, políticas e culturais. Observamos isso tanto na crescente participação política partidária, quanto nas mobilizações de diversos grupos religiosos na opinião pública a respeito de direitos reprodutivos, direitos humanos, direitos e respeito às minorias, por exemplo, e não por acaso, também no campo pedagógico. Já não é de hoje, aliás, que boa parte da literatura dedicada ao fenômeno religioso destaca a intensificação da ocupação do espaço público por parte dos atores religiosos: com cada vez maior frequência, eles atuam nas praças e estádios, mobilizam as mídias eletrônicas, impressas e digitais (CUNHA, 2007).

Outro ponto que integra a agenda de pesquisa dos estudiosos da religião e que é do interesse dos profissionais da Educação diz respeito à multiplicidade das formas com que são compostas as experiências religiosas na contemporaneidade. Há inúmeras pesquisas, por exemplo, que indicam que, especialmente entre os jovens, a vivência religiosa ocorreria especialmente a partir de hibridações e intercâmbios, além de ser cada vez mais comum ocorrer o que se convencionou chamar na literatura de "trânsito religioso" (ALMEIDA; MONTERO, 2001) e a "dupla filiação" (ou tripla, ou múltipla), envolvendo a mudança de práticas e crenças em relação à herança religiosa familiar, bem como o surgimento de um número cada vez mais expressivo dos "sem religião" e dos "evangélicos genéricos", isto é, indivíduos que não se identificam ou se filiam a instituições religiosas específicas, embora mantenham ativas as relações com divindades e a concordância com certa cosmologia religiosa (quase sempre de matriz cristã) (cf. NOVAES, 2004; CAMURÇA, 2017).

Todo esse arcabouço serviu de apoio para nossa pesquisa, que pretendeu, por um lado, mapear a diversidade religiosa entre estudantes da UFPR matriculados em Curitiba e, por outro lado, procurou estabelecer relações entre a vivência religiosa e a vida universitária. Neste artigo compartilharemos com as e os leitores algumas notas sobre o desenho de nossa pesquisa, nossas estratégias de investigação e os resultados preliminares sobre vínculos religiosos, frequência

públicas e privadas nos Estados Unidos entre 2003 e 2008, resultando na publicação de Astin et al. (2011). Os resultados estão disponíveis em: https://www.spirituality.ucla.edu/. Acesso em: 02 abr. 2020. Em nosso levantamento da bibliografia nacional localizamos, até o momento, poucos estudos que mapeiam as filiações religiosas do conjunto de estudantes de uma instituição de ensino. Destacamos, nesse sentido, o trabalho de Pitta et al. (2007). 
e pertencimento religioso dos estudantes da UFPR, propondo a comparação entre bacharelado e licenciatura.

\section{Delineando a pesquisa e os procedimentos de trabalho}

O tema da diversidade religiosa em instituições de ensino superior brasileiras tem sido abordado, sobretudo, por meio de levantamentos que visam traçar o perfil religioso dos estudantes de cursos específicos, tais como o trabalho pioneiro de Novaes (1994), seguido pelos de Steil, Alves e Herreira (2001)3 , Simões (2007), Junqueira e Teófilo (2013), Mori e Silva (2016), Pereira e Holanda (2016), Mezzomo, Pátaro e Rosa (2017a, 2017b) e Swatowiski, Silva e Alvarenga (2018).

Esse conjunto de surveys inspirou o desenho de nossa pesquisa, porém, de modo diverso, ela não se detém em cursos específicos. Como um dos objetivos gerais do levantamento consistiu em produzir dados sobre o panorama religioso da UFPR, em resposta a demandas institucionais acerca do perfil religioso discente (SCHELIGA; KNOBLAUCH; BELLOTTI, 2018), isso nos direcionou aos setores que agregam cursos afins ${ }^{4}$. Essa estratégia nos permitiu, a um só tempo, ter uma visão do conjunto da universidade e também garantir uma amostra diversificada.

Em que pesem os distintos prestígios que cada carreira universitária goza e as características específicas de cada curso (quanto ao perfil socioeconômico de seu corpo discente e docente, número de vagas abertas, concorrência nos processos seletivos, turno ofertado e índice de evasão, por exemplo), a pesquisa realizada não permite aprofundamentos sobre essas questões particulares, nem era este o seu escopo inicial, como sublinhamos acima. Os dados do survey permitem, contudo, identificar tendências gerais sobre o comportamento religioso entre universitários, bem como fazer inferências a respeito do peso

3 A pesquisa de Steil et al. foi desdobrada nos comentários de Camurça (2001), Jungblut (2001), Lewgoy (2001), Gaiger, Locks e Silva (2001) e Cardoso, Perez e Oliveira (2001).

4 A Universidade Federal do Paraná está dividida em 14 setores: Artes, Comunicação e Design; Agrárias; Ciências Biológicas; Ciências Sociais Aplicadas; Exatas; Ciências Jurídicas; Ciências da Saúde; Ciências Humanas; Ciências da Terra; Educação Profissional e Tecnológica; Educação; Tecnologia; Setor Palotina e Setor Litoral. A pesquisa foi realizada em 12 dos 14 setores, excluindo os dois últimos, que não se encontram em Curitiba. Tal exclusão deu-se pela indisponibilidade de financiamento para o levantamento de dados em outros municípios. Isso não impactou os dados obtidos, considerando o fato de a maioria dos estudantes da UFPR se concentrar nos campi de Curitiba 
(relativo) da religião nos processos de formação de professores, indicando semelhanças e dessemelhanças entre os que optam, na entrada ou no decorrer do curso $^{5}$, pelo bacharelado ou licenciatura.

A diferença de foco não foi o único limite para um eventual exercício de comparação entre os nossos dados e os produzidos pelos colegas supracitados: a grande variação que identificamos nesse rol de pesquisas - seja em relação ao escopo dos surveys, seja em relação às metodologias de produção de dados adotadas ou, ainda, ao modo como os dados foram analisados - demanda um esforço que ultrapassa os limites desse nosso exercício, de modo que eventuais aproximações entre os resultados obtidos nestes diferentes levantamentos só poderão ser realizadas futuramente. De modo análogo, as comparações com os dados do Censo de 2010 requerem algumas mediações: muito embora algumas tendências gerais captadas pela pesquisa do Instituto Brasileiro de Geografia e Estatística (IBGE) possam servir de guia geral para a análise de nossos dados, sempre faremos ponderações sobre as especificidades de nossas questões e de nossa amostra, de modo a contextualizar os dados que apresentaremos na sequência.

A amostra de 385 entrevistados, calculada com apoio de Nivea da Silva Matuda, docente do Departamento de Estatística de nossa instituição de ensino, foi estratificada por Setor, habilitação do curso (bacharelado ou licenciatura) e gênero do participante, a partir do número geral de matrículas fornecido pelo Núcleo de Assuntos Acadêmicos da UFPR. O plano amostral inclui 304 estudantes do bacharelado e 81 das licenciaturas (representando, respectivamente, $79 \%$ e $21 \%$ das matrículas em cada habilitação). A margem de erro estabelecida para a amostra foi de 5\%, com nível de confiança de $95 \%$.

$\mathrm{O}$ instrumento de pesquisa foi validado após três sucessivas rodadas de pré-teste. A aplicação ocorreu entre o segundo semestre de 2018 e o primeiro semestre de 2019. O questionário aplicado continha dezenove questões, entre perguntas abertas e fechadas (com resposta única ou múltipla escolha), abrangendo concepções de espiritualidade e religião, elenco de práticas acadêmicas e religiosas, percepções sobre intolerância religiosa no âmbito da

5 Na UFPR há cursos nos quais as e os estudantes optam, ainda no processo seletivo, por uma das duas habilitações, sendo facultado ao discente solicitar a reopção no decorrer do mesmo (bem como realizar complementação de estudos, cursando a segunda habilitação após concluir a primeira). Em outros, a opção pela habilitação é realizada apenas ao término do núcleo comum, geralmente na passagem do segundo para o terceiro ano. Por ocasião da aplicação de nossa pesquisa, também nos deparamos com estudantes que cursavam as duas habilitações simultaneamente. Para os fins de cálculo da amostra, as e os estudantes com dupla habilitação foram contabilizados como estudantes de Licenciatura, de modo a observar relações entre vínculo religioso e o percurso de formação de professores. 
UFPR, frequência a instituições religiosas e vínculos com grupos religiosos que atuam no espaço universitário, relações estabelecidas entre fé e conhecimento, além de questões de caracterização da pessoa que participou da pesquisa. Em função dos limites deste artigo, apresentaremos apenas as análises relativas à declaração de vínculo religioso, a frequência em grupo(s) religioso(s) no ano de 2018, a frequência religiosa após o ingresso na universidade e a filiação religiosa institucional das e dos discentes.

Os questionários foram aplicados com a mediação de estudantes recrutados especificamente para essa tarefa. Optamos pela aplicação presencial como estratégia para garantir a representatividade por setor, habilitação e gênero e, ao mesmo tempo, assegurar a aleatoriedade dentro das cotas pré-definidas ${ }^{6}$. O formulário ficou disponível na plataforma Google Forms, com acesso restrito aos aplicadores, gerando banco de dados que foi consolidado em 2019.

\section{Os dados}

Os últimos levantamentos estatísticos sobre religião/religiosidade mostram que o cenário religioso está mudando no Brasil. Depois de uma história de mais de quatrocentos anos de hegemonia católica, nas últimas quatro décadas observa-se uma significativa diminuição do número de indivíduos que se declaram católicos, atualmente $64,6 \%$ da população, segundo o censo de 2010 (IBGE, 2010). Por sua vez, os evangélicos cresceram a $22,2 \%$ da população em 2010, sendo que a sua maioria é constituída de pentecostais, seguidos de uma minoria de evangélicos de missão (ou protestantes históricos) e evangélicos sem uma denominação específica ${ }^{7}$. Já os adeptos da umbanda e do candomblé

6 Por ocasião da pesquisa, na capital paranaense eram ofertados cerca de 60 cursos de graduação - alguns dos quais desdobrados em dois ou mais itinerários formativos, como é o caso de Letras que aqui, de modo simplificado, estamos considerando como um único curso de graduação. Respeitadas as cotas de pesquisa, orientamos os aplicadores a adotarem, durante a aplicação da pesquisa, procedimentos randômicos para seleção dos entrevistados, de modo a evitar a concentração de respostas em grupos seletos. A orientação foi bem-sucedida, considerando que nosso banco de dados tem respostas de estudantes de praticamente todos os cursos de Bacharelado (ao menos um estudante de cada curso) e de todas as Licenciaturas (a saber: Artes Visuais; Ciências Biológicas; Ciências Sociais; Educação Física; Enfermagem; Filosofia; Física; Geografia; História; Letras; Matemática; Música; Pedagogia e Química).

7 Para mais detalhes sobre as diferenças entre evangélicos de missão, pentecostais ou neopentecostais, sugerimos a consulta aos trabalhos de Freston (1993), Mariano (1999) e Mendonça e Velasques Filho (2002). 
correspondem a cerca de $2 \%$ da população desde o Censo de 2000 , enquanto crescem os chamados sem religião, estimado em $8 \%$ da população em $2010^{8}$.

Debates em torno do censo religioso de 2000 e de 2010 (MAFRA, 2004; TEIXEIRA; MENEZES, 2013; MENEZES, 2014) convergem em um ponto: as pesquisas de larga escala costumam apontar determinadas tendências e filiações religiosas, a partir da auto declaração dos respondentes, mas não possuem instrumentos para explorar as nuances das vivências religiosas. No censo do IBGE, a pergunta feita na amostra sorteada para responder o questionário mais extenso é: “qual é sua fé ou crença religiosa?". Se, por um lado, isso oferece uma gama de respostas que abrange uma grande diversidade de denominações e grupos religiosos, por outro não permite que certas omissões sejam detectadas um caso típico é a do baixo número de respostas confirmando adesão à umbanda e ao candomblé, por exemplo. Mesmo com o fato de o questionário ser anônimo, estudiosos das religiões de matriz africana afirmam que é possível haver um número maior de praticantes dessas religiões que preferem não explicitar sua pertença religiosa com medo de preconceito (PRANDI, 2013).

Interessadas em obter respostas que permitissem qualificar, de algum modo, os vínculos religiosos, optamos por uma questão diversa da do Censo, desdobrando nossa pergunta em dois sentidos: o do pertencimento e o da participação regular em um grupo religioso. Também optamos por situar as respostas, adotando o ano de 2018 como marco temporal dos vínculos. Desta forma, em lugar de perguntarmos diretamente "qual é sua fé ou crença religiosa?", nossa questão foi assim formulada: "Tendo como referência o ano de 2018, você diria que pertence a e/ou participa de forma regular de algum grupo de caráter religioso ou de uma instituição religiosa? Leia as alternativas neste cartão e escolha aquela que melhor representa a sua opinião atual".

As cinco possibilidades de respostas propostas por nós, formuladas após a fase de pré-teste da pesquisa, alinharam-se ao objetivo de captar nuances das filiações religiosas. A primeira das alternativas apresentava a possibilidade de o respondente indicar um vínculo religioso não institucional, o que a literatura da área de estudos da religião vem classificando como o "crer sem pertencer" (DAVIE, 1990; FULLER, 2001) ${ }^{9}$. A segunda delas explorava o ateísmo como

8 Pesquisa do Datafolha realizada com 2.948 entrevistados em 176 municípios de todo o país, entre 5 e 6 de dezembro de 2019, apontou para a manutenção das três tendências já identificadas nos últimos censos realizados pelo IBGE: crescimento evangélico, declínio do número de católicos e aumento do número dos sem-religião (respectivamente: $31 \%, 50 \%$ e $10 \%$ da amostra). A enquete do Datafolha identificou um total de 3\% de espíritas, $2 \%$ de adeptos das religiões afro-brasileiras e $1 \%$ de indivíduos que se declaram ateus (BALLOUSIER, 2020).

9 O cruzamento com outros dados da pesquisa, tais como as concepções de religião e espiritualidade, bem como o engajamento com atividades religiosamente orientadas, nos ajuda a 
possibilidade de resposta, levando em conta os dados preliminares de nosso survey, que nos sugeriam que uma parcela significativa dos pesquisados explicitava uma rejeição a qualquer tipo de vínculo com organizações de natureza religiosa. As três últimas alternativas, por sua vez, indicavam pertença e participação em grupos religiosos, destacando posicionamentos exclusivistas, cambiantes ou múltiplos. Os dados consolidados estão na tabela abaixo:

TABELA 1 - VÍNCULOS RELIGIOSOS EM 2018, UFPR CURITIBA (N = 385)

\begin{tabular}{|l|c|c|c|c|c|c|}
\hline \multirow{2}{*}{ Vínculos religiosos em 2018 } & \multicolumn{2}{|c|}{ Bacharelado } & \multicolumn{2}{c|}{ Licenciatura } & \multicolumn{2}{c|}{ Amostra Geral } \\
\cline { 2 - 7 } & $\mathrm{F}$ & $\%$ & $\mathrm{~F}$ & $\%$ & $\mathrm{~F}$ & $\%$ \\
\hline $\begin{array}{l}\text { Não. Acredito em deus e/ou em uma } \\
\text { força superior/transcendente, mas não } \\
\text { participo de nenhum grupo religioso. }\end{array}$ & 129 & $42,43 \%$ & 29 & $35,80 \%$ & 158 & $41,04 \%$ \\
\hline $\begin{array}{l}\text { Não. Sou ateu e não participo de } \\
\text { grupos religiosos. }\end{array}$ & 60 & $19,74 \%$ & 19 & $23,46 \%$ & 79 & $20,52 \%$ \\
\hline $\begin{array}{l}\text { Sim. Participo de mais de um grupo } \\
\text { religioso, mas de modo alternado. }\end{array}$ & 6 & $1,98 \%$ & 2 & $2,47 \%$ & 8 & $2,08 \%$ \\
\hline $\begin{array}{l}\text { Sim. Participo de um único grupo } \\
\text { religioso específico. }\end{array}$ & 102 & $33,55 \%$ & 27 & $33,33 \%$ & 129 & $33,50 \%$ \\
\hline $\begin{array}{l}\text { Sim. Participo de vários grupos } \\
\text { religiosos simultaneamente. }\end{array}$ & 7 & $2,30 \%$ & 4 & $4,94 \%$ & 11 & $2,86 \%$ \\
\hline Total & $\mathbf{3 0 4}$ & $\mathbf{1 0 0 , 0 0 \%}$ & $\mathbf{8 1}$ & $\mathbf{1 0 0 , 0 0 \%}$ & $\mathbf{3 8 5}$ & $\mathbf{1 0 0 , 0 0 \%}$ \\
\hline
\end{tabular}

FONTE: As autoras (2019).

Analisando primeiramente os números totais de nossa amostra, obtivemos $38 \%$ de respostas que indicam algum vínculo religioso, sendo alternado, exclusivista ou simultâneo - ou seja, quase 4 em cada 10 universitários afirmaram pertencer e/ou participar de grupos religiosos. Um em cada cinco estudantes de nossa amostra afirmou ser ateu. Mais de $40 \%$ dos entrevistados, por sua vez, declarou não participar de nenhum grupo religioso, embora acredite em deus ou em uma força transcendente.

Nessa tabulação, não identificamos diferenças estatisticamente significativas nas respostas segundo a habilitação (licenciatura ou bacharelado). Se somarmos as três últimas alternativas de resposta, por exemplo, temos percentuais de resposta muito semelhantes nos dois grupos: $37,95 \%$ no dos alunos do bacharelado e $40,25 \%$ no dos alunos de licenciatura. Neste conjunto

compreender que há uma gama bastante variada de entendimentos sobre esta questão. Identificamos, assim, concepções e práticas que poderíamos interpretar como agnósticas ao lado de outras, cujos sentidos são mais fluidos e escapam a classificações rígidas. Em comum, como destacado, há um afastamento de uma vivência religiosa de modo institucionalizado. 
dos que responderam "sim", destaca-se também a forma de participação predominante identificada: um terço dos respondentes de cada uma das habilitações apontou ter um vínculo religioso de caráter mais exclusivista, isto é, quando se frequenta apenas um único grupo religioso. Essa resposta parece, à primeira vista, relativizar a hipótese de que a religiosidade da juventude seria predominantemente sincrética ou híbrida.

Observando os dados gerais de nosso survey podemos, no entanto, captar uma outra tendência já identificada tanto na literatura quanto nos dados empíricos dos últimos censos brasileiros: a desfiliação religiosa. $O$ debate sobre secularização serve como pano de fundo para essas discussões (BERGER, 2000, 2012; CASANOVA, 1994; PIERUCCI, 1997; MARIZ, 2000) que, em comum, indicam para uma nova forma de se relacionar com a religião. Uma parcela dos estudos sociológicos destaca o quanto a religião na modernidade estaria baseada mais na experiência e autonomia individual e na espontaneidade. Essa tendência conviveria, paradoxalmente, com a permanência das instituições e a centralidade do cristianismo no cenário cultural e religioso brasileiro (SANCHIS, 2008). Ao lado do "secularismo à brasileira" e de uma nova interpretação para o conceito de diversidade, novos desafios se põem à defesa da laicidade num momento em que, no contexto nacional, novas e delicadas relações se estabelecem entre política e religião (NOVAES, 2014).

Ainda que nossa indagação tenha sido diferente em relação àquela feita por ocasião do censo de 2010, podemos estabelecer nexos com os números daqueles que se declararam sem religião no levantamento nacional, observando também em nossa pesquisa os efeitos da redefinição dos vínculos religiosos por meio de rearranjos pessoais (HERVIEU-LÉGER, 1999; TEIXEIRA, 2014). Em nossa amostra, cerca de 4 em cada 10 estudantes assinalaram a primeira alternativa de resposta, indicando uma vivência mais fluida e menos institucionalizada com a religião. Nossos dados acompanham, assim, as reflexões de Novaes (2004) e de Camurça (2017) sobre as experiências religiosas juvenis, nas quais destacam o expressivo aumento do número dos "sem religião" nessa camada etária. $\mathrm{Na}$ comparação entre os dois itinerários de formação nota-se uma pequena diferença: obtivemos um número de respostas relativas aos "sem religião" ligeiramente maior no grupo dos estudantes do bacharelado (cerca de $42 \%$ de respostas contra quase $36 \%$ no grupo dos estudantes de licenciatura).

Notamos ainda que em nossa amostra obtivemos cerca de $20 \%$ de respostas de estudantes que se intitulam "ateus". Como mencionado anteriormente, a inclusão da categoria ateu nas alternativas de resposta foi fruto do próprio processo de pesquisa: na fase de pré-testes, obtivemos muitas menções espontâneas que apontavam para a mobilização dessa categoria como central para a definição de uma identidade religiosa e isso nos levou a querer testá-la, 
estimulando a resposta. Nessa primeira tabulação não identificamos diferenças estatisticamente relevantes nos dois conjuntos de estudantes: em cada um dos grupos, cerca de um em cada cinco discentes declarou-se ateu.

Declarar-se ateu, no entanto, não deve ser lido como um afastamento sistemático do universo das práticas religiosas, tampouco como efeito da entrada em um ambiente pautado por princípios laicos, como se presume no senso comum. Embora muitos dos respondentes confirmem, em outro momento do questionário, que não frequentam regularmente grupos religiosos (e tampouco o frequentavam antes de ingressar na universidade, como se verá adiante), as respostas dadas a uma outra questão de nossa pesquisa nos mostraram que muitos dos que se declaram ateus compartilham com os colegas que afirmam ter uma pertença religiosa um amplo repertório de ações. Ou seja: em algum momento de 2018 muitos destes estudantes que se declararam ateus, bem como os que podem ser classificados como "sem religião", engajaram-se esporadicamente em grupos de sociabilidade religiosamente orientados, consumiram mídia religiosa, participaram de ações de caridade promovidos por grupos religiosos e, sobretudo, conversaram sobre religião com seus amigos. Isso abre uma pista importante para pensamos sobre o uso social da categoria "ateu" no ambiente universitário, sugerindo haver uma forte rejeição por parte desses estudantes à vinculação estrita com um grupo religioso, portanto uma rejeição à identificação com uma igreja ou comunidade religiosa, o que aproxima esse grupo ao dos "sem religião".

Voltemos agora aos nossos dados. A fim de qualificar a experiência de participação religiosa, perguntamos ao subgrupo que respondeu ter vínculos religiosos qual era a frequência de participação neste grupo ou organização. Novamente usamos o expediente de mostrar aos entrevistados uma lista com algumas alternativas de respostas, pedindo a indicação da que mais condizia com sua experiência. Reproduzimos abaixo os resultados:

TABELA 2 - FREQUÊNCIA EM GRUPO RELIGIOSO, UFPR CURITIBA (N =148)

\begin{tabular}{|l|c|c|c|c|c|c|}
\hline \multirow{2}{*}{ Frequência } & \multicolumn{2}{|c|}{ Bacharelado } & \multicolumn{2}{c|}{ Licenciatura } & \multicolumn{2}{c|}{ Subamostra } \\
\cline { 2 - 7 } & $\mathrm{F}$ & $\%$ & $\mathrm{~F}$ & $\%$ & $\mathrm{~F}$ & $\%$ \\
\hline Diariamente. & 3 & $2,61 \%$ & 0 & $0,00 \%$ & 3 & $2,03 \%$ \\
Mais de uma vez por semana. & 24 & $20,87 \%$ & 10 & $30,30 \%$ & 34 & $22,97 \%$ \\
Uma vez por semana. & 43 & 37,39 & 12 & $36,37 \%$ & 55 & $37,16 \%$ \\
Uma vez por mês. & 28 & $24,35 \%$ & 4 & $12,12 \%$ & 32 & $21,62 \%$ \\
Algumas vezes por ano. & 15 & $13,04 \%$ & 7 & $21,21 \%$ & 22 & $14,87 \%$ \\
Não frequento o grupo/organização. & 2 & $1,74 \%$ & 0 & $0,00 \%$ & 2 & $1,35 \%$ \\
Total & $\mathbf{1 1 5}$ & $\mathbf{1 0 0 , 0 \%}$ & $\mathbf{3 3}$ & $\mathbf{1 0 0 , 0} \%$ & $\mathbf{1 4 8}$ & $\mathbf{1 0 0 , 0 \%}$ \\
\hline
\end{tabular}

FONTE: As autoras (2019). 
Obtivemos um total de 148 respostas. Nesta subamostra, mais de $60 \%$ das ocorrências refere-se à participação em atividades religiosas com alta frequência ou frequência regular (isto é, diariamente, mais de uma vez por semana ou, no mínimo, uma vez por semana). Comparando os resultados das duas habilitações, chama a nossa atenção que $30 \%$ dos estudantes da licenciatura participam de atividades de caráter religioso mais de uma vez por semana; em contraste, essa alternativa foi assinalada por $20 \%$ dos estudantes do bacharelado. A participação mensal, por sua vez, obteve o dobro de respostas no grupo dos discentes do bacharelado em relação aos licenciandos.

Se, portanto, a Tabela 1 nos permitiu perceber que os estudantes de ambas as habitações apresentavam padrão de resposta bastante parecido à questão sobre vínculos religiosos, a Tabela 2 nos trouxe a indicação de uma diferença instigante para a nossa reflexão sobre a formação de professores: discentes dos cursos de licenciatura tendem a participar com maior frequência e regularidade das atividades religiosas em suas comunidades de fé, em comparação a seus colegas do bacharelado.

Os dados que produzimos nos sugerem que os elos estabelecidos pelos estudantes entre vida universitária e vida religiosa são múltiplos e complexos. Tendo isso em vista, pedimos aos entrevistados que indicassem se, após ingressar na UFPR, a frequência a atividades religiosas teria aumentado, diminuído ou permanecido a mesma (aqui desdobrada em duas opções: mantendo-se tão ausente ou tão constante quanto era antes do ingresso na instituição). Logo de saída, nota-se que para quase dois terços de nossa amostra o ingresso na instituição de ensino superior não alterou a frequência a grupos religiosos: cerca de $36 \%$ já não frequentava regularmente grupos religiosos e para $26 \%$ a frequência se manteve igual ao que costumava ocorrer no período préuniversitário. Quando convidados a justificar sua resposta, de modo espontâneo, muitos destes estudantes sustentaram que a universidade não interfere nas práticas religiosas em suas vidas, não produzindo efeitos sobre o tempo dedicado às atividades de natureza religiosa. Tampouco reconhecem existir conflitos entre discurso religioso e conhecimento secular, concedendo a cada qual um estatuto específico.

Os dados da Tabela 3 nos permitem novamente observar nuances interessantes nas respostas dadas pelos estudantes de cada um dos itinerários formativos, indicando que estudantes da licenciatura tendem a ter vivências religiosas mais intensas, por assim dizer. Como se lê na Tabela 3, quase 32\% dos alunos do bacharelado destacou que, após o ingresso na instituição de ensino, passou a participar com menos frequência de atividades religiosas. No caso dos alunos da licenciatura, essa proporção diminui para $23 \%$, ou seja, cerca de um quarto dos estudantes (e não de quase $1 / 3$, como no grupo dos bacharelandos). 
TABELA 3 - ALTERAÇÕES NA FREQUÊNCIA A GRUPOS RELIGIOSOS - UFPR CURITIBA $(\mathrm{N}=385)$

\begin{tabular}{|l|c|c|c|c|c|c|}
\hline Frequência religiosa & \multicolumn{2}{|c|}{ Bacharelado } & \multicolumn{2}{|c|}{ Licenciatura } & \multicolumn{2}{c|}{ Amostra Geral } \\
\hline & $\mathrm{F}$ & $\%$ & $\mathrm{~F}$ & $\%$ & $\mathrm{~F}$ & $\%$ \\
\hline Aumentou após ingressar na UFPR & 19 & $6,25 \%$ & 7 & $8,64 \%$ & 26 & $6,75 \%$ \\
\hline Diminuiu após ingressar na UFPR & 96 & $31,58 \%$ & 19 & $23,46 \%$ & 115 & $29,88 \%$ \\
\hline $\begin{array}{l}\text { Não frequentava antes de } \\
\text { ingressar na UFPR e continuo não } \\
\text { frequentando }\end{array}$ & 106 & $34,87 \%$ & 32 & $39,50 \%$ & 138 & $35,84 \%$ \\
\hline $\begin{array}{l}\text { Permaneceu a frequência de antes } \\
\text { de ingressar na UFPR }\end{array}$ & 83 & $27,30 \%$ & 23 & $28,40 \%$ & 106 & $27,53 \%$ \\
\hline Total & $\mathbf{3 0 4}$ & $\mathbf{1 0 0 , 0 0 \%}$ & $\mathbf{8 1}$ & $\mathbf{1 0 0 , 0 0 \%}$ & $\mathbf{3 8 5}$ & $\mathbf{1 0 0 , 0 0 \%}$ \\
\hline
\end{tabular}

FONTE: As autoras (2019).

Vejamos agora um detalhe da subamostra formada pelos respondentes que indicaram ter reduzido a frequência a grupos religiosos. O principal motivo apontado pelos alunos dos diferentes cursos de bacharelado para diminuir a frequência a grupos religiosos foi a falta de tempo ( $48 \%$ das respostas), índice um pouco acima do encontrado no subgrupo das licenciaturas (42\% alunos justificaram dessa forma). Se a alegada falta de tempo aproxima os dois grupos, outras razões os distinguem: apenas 6 estudantes do bacharelado apontaram os conhecimentos adquiridos na universidade como razão para essa diminuição (cerca de 6\%), mas 7 estudantes das licenciaturas o fizeram - o que equivale a quase $37 \%$ daqueles que justificaram dessa forma entre os alunos das diferentes licenciaturas, índice de respostas bastante próximo ao da "falta de tempo".

Os números absolutos são bastante baixos - no total de 385 alunos, apenas 13 alunos licenciandos e bacharelandos justificaram dessa forma-, mas quando fazemos a distinção segundo o percurso formativo, não deixa de ser interessante observar que essa última justificativa tem um índice muito mais representativo entre os alunos das licenciaturas que no subgrupo do bacharelado. Um primeiro impulso é ler esse dado como indício de um maior reconhecimento de conflitos entre fé e conhecimento secular por parte dos estudantes da licenciatura, mas não se pode dar esse passo sem muita cautela: os dados produzidos ainda não nos permitem nem compreender a fundo a natureza deste conflito, nem seus efeitos nas diversas carreiras de formação de professores.

Também não podemos deixar de ressaltar que, entre os estudantes das licenciaturas, a maior parte continua frequentando seus respectivos grupos religiosos com a mesma intensidade de antes do ingresso à universidade. Tampouco deixamos de notar que o percentual de respondentes que indicou aumento da frequência foi ligeiramente maior na licenciatura em comparação 
com o bacharelado, fato que é justificado pelos estudantes por meio do destaque às questões pessoais relacionadas às dificuldades ocasionadas pela vida universitária que se convertem em quadros que afetam a saúde mental. Este conjunto de dados que indicam uma participação religiosa mais tensa e/ou intensa entre estudantes das diferentes licenciaturas, futuros professores, é uma pista que esperamos poder seguir em trabalhos futuros, de modo a aprofundar essa relação que parece estar se estabelecendo entre docência e religião.

Finalmente, comentamos os resultados da filiação religiosa declarada, obtidos em 148 respostas das pessoas que responderam "sim" à frequência ou adesão a um ou mais grupos religiosos em 2018. Os respondentes que se disseram católicos e indicaram a igreja que frequentam, foram classificados como Católicos. No caso evangélico, agrupamos para esta apresentação os que se autodeclararam tanto "evangélicos" quanto frequentadores de igrejas reconhecidamente evangélicas; na nossa amostra, foram declaradas participações em igrejas pentecostais (Assembleia de Deus, Igreja do Evangelho Quadrangular, Igreja Universal do Reino de Deus, etc.), igrejas protestantes históricas ou evangélicas de missão (Luterana, Presbiteriana, Batista), dentre outras. Os demais grupos identificados foram hinduísmo, budismo, umbanda (com destaque para o fato de que não houve nenhuma declaração espontânea de adesão ao candomblé), espiritismo, Testemunhas de Jeová e Mórmons (Igreja de Jesus dos Santos dos Últimos Dias). Por fim, também foram identificados adeptos das, assim chamadas pelos pesquisadores do IBGE, religiões indígenas (Santo Daime e Ayahuasca) e religiões orientais (Taoísmo, Mahiraki, Hare Krishna).

Tanto na licenciatura quanto no bacharelado observamos uma predominância de cristãos, distribuídos entre católicos, evangélicos e outras religiões cristãs (Testemunhas de Jeová, Adventistas de Sétimo Dia, Mórmons e cristãos sem declaração de uma denominação específica). Isso se segue a uma participação minoritária em outras religiões, como a umbanda, o espiritismo, religiões orientais e indígenas. Nota-se, ainda, uma ampla predominância do catolicismo entre estudantes do bacharelado (pouco mais de 40\%) e uma adesão católica menor entre alunos da licenciatura (menos de $20 \%$ dos estudantes desta modalidade). Tendência oposta ocorre no caso dos evangélicos, somando-se os números dos evangélicos de missão, os pentecostais e os de religião evangélica não determinada: no bacharelado encontramos cerca de $28 \%$ de estudantes que se declaram evangélicos, com proporção semelhante de protestantes históricos e pentecostais; já na licenciatura, o percentual de evangélicos salta para cerca de $36 \%$, predominando a identificação de vínculos com igrejas pentecostais. Dentre os licenciandos, nota-se, portanto, um índice percentual quase duas vezes superior de evangélicos em relação aos católicos. Também é interessante notar que o percentual de cristãos, somados os números de Testemunhas de Jeová, 
TABELA 4 - FILIAÇÃO INSTITUCIONAL - UFPR CURITIBA (N = 148)

\begin{tabular}{|l|c|c|c|c|c|c|}
\hline \multirow{2}{*}{ Filiação institucional } & \multicolumn{2}{|c|}{ Bacharelado } & \multicolumn{2}{|c|}{ Licenciatura } & \multicolumn{2}{c|}{ Subamostra } \\
\cline { 2 - 7 } & $\mathbf{F}$ & $\mathbf{\%}$ & $\mathbf{F}$ & $\mathbf{\%}$ & $\mathbf{F}$ & $\mathbf{\%}$ \\
\hline Budismo & 1 & $0,87 \%$ & 1 & $3,03 \%$ & 2 & $1,35 \%$ \\
\hline Católica & 50 & $43,48 \%$ & 6 & $18,19 \%$ & 56 & $37,84 \%$ \\
\hline $\begin{array}{l}\text { Cristão - Igreja de Jesus dos Santos dos } \\
\text { Útimos Dias }\end{array}$ & 0 & $0,00 \%$ & 1 & $3,03 \%$ & 1 & $0,68 \%$ \\
\hline $\begin{array}{l}\text { Cristão - Religiosidade Cristã Não } \\
\text { Determinada }\end{array}$ & 2 & $1,74 \%$ & 1 & $3,03 \%$ & 3 & $2,02 \%$ \\
\hline Cristão - Testemunha de Jeová & 2 & $1,74 \%$ & 1 & $3,03 \%$ & 3 & $2,02 \%$ \\
\hline Declaração Múltipla de religiosidade & 11 & $9,57 \%$ & 5 & $15,15 \%$ & 16 & $10,81 \%$ \\
\hline Espírita & 6 & $5,22 \%$ & 2 & $6,06 \%$ & 8 & $5,40 \%$ \\
\hline Evangélica não determinada & 3 & $2,60 \%$ & 4 & $12,12 \%$ & 7 & $4,73 \%$ \\
\hline Evangélico - Pentecostal & 15 & $13,04 \%$ & 7 & $21,21 \%$ & 22 & $14,86 \%$ \\
\hline Evangélico de missão & 14 & $12,17 \%$ & 1 & $3,03 \%$ & 15 & $10,14 \%$ \\
\hline Fundamentalismo & 1 & $0,87 \%$ & 0 & $0,00 \%$ & 1 & $0,68 \%$ \\
\hline Novas religiões orientais & 2 & $1,74 \%$ & 0 & $0,00 \%$ & 2 & $1,35 \%$ \\
\hline Outras religiões orientais & 1 & $0,87 \%$ & 0 & $0,00 \%$ & 1 & $0,68 \%$ \\
\hline Sem declaração & 0 & $0,00 \%$ & 1 & $3,03 \%$ & 1 & $0,68 \%$ \\
\hline Tradições indígenas & 1 & $0,87 \%$ & 0 & $0,00 \%$ & 1 & $0,68 \%$ \\
\hline Umbanda & 6 & $5,22 \%$ & 3 & $9,09 \%$ & 9 & $6,08 \%$ \\
\hline Total & $\mathbf{1 1 5}$ & $\mathbf{1 0 0 , 0 0 \%}$ & $\mathbf{3 3}$ & $\mathbf{1 0 0 , 0 0 \%}$ & $\mathbf{1 4 8}$ & $\mathbf{1 0 0 , 0 0 \%}$ \\
\hline
\end{tabular}

FONTE: As autoras (2019).

Mórmons e de Religiosidade Cristã Não Determinada, é quase o triplo na licenciatura em relação ao bacharelado. Constatamos também maior ocorrência de declarações de múltipla religiosidade, categoria utilizada pelo IBGE para classificar os casos de duplo ou múltiplo pertencimento, entre os alunos da licenciatura; assim como há, proporcionalmente neste subgrupo, maior número de estudantes que explicitam vínculos com a umbanda, tanto como sua única religião (aproximadamente $9 \%$ na licenciatura contra 5\% no Bacharelado), quanto como uma das religiões com as quais mantém vínculo.

Nos casos relatados de duplo ou múltiplo pertencimento, pudemos observar que as combinações de participação em diferentes grupos religiosos seguem alguns padrões já identificados na literatura, como as associações entre catolicismo e umbanda, e catolicismo e espiritismo, por exemplo. Dentre as combinações apontadas pelos estudantes, chama a nossa atenção dois clusters, em particular: um, no qual se incluem, mais frequentemente, praticantes de umbanda e de religiões orientais e outro, que incluem evangélicos ou católicos. 
Quando comparados esses dois subgrupos, observamos que os padrões de associação religiosa se modificam ligeiramente. Os estudantes evangélicos tendem a circular mais estritamente pelo universo dos grupos protestantes e pentecostais, assim como os católicos associam-se mais frequentemente a grupos religiosos que partilham elementos da cosmologia cristã. Há, claro, exceções, mas de modo geral os fluxos religiosos orientam-se, portanto, dentro de um espectro menos amplo se comparado àquele dos estudantes filiados a religiões de matriz não cristã. Reitera-se, portanto, a predominância de um exclusivismo religioso: os entrevistados tendem a frequentar somente o seu próprio grupo religioso, poucos são os que circulam por mais de um grupo e, quando o fazem, tendem a associar religiões afins.

\section{Algumas considerações}

Nossos dados corroboram duas tendências apontadas por cientistas sociais da religião: de um lado, identificamos dentre os alunos cristãos (isto é, católicos e, especialmente, entre evangélicos) da UFPR uma forte vivência exclusivista com seus respectivos grupos religiosos; por outro lado, também identificamos um alto índice de estudantes que se declaram "sem religião" ou ateus, exemplos vivos daquilo que a literatura consagra em termos dos "ventos secularizantes" (NOVAES, 2004) e de uma "secularização subjetiva" (CAMURÇA, 2017). A coexistência dessas duas tendências em nossa amostra nos permite demonstrar, justamente, não ser possível enquadrar o comportamento religioso juvenil em apenas uma ou outra direção: nem só de hibridações e apropriações individuais se faz a experiência religiosa dos universitários, uma vez que muitos se mostram atados a laços estáveis com um grupo religioso circunscrito; tampouco as formas tradicionais de vinculação religiosa são satisfatórias para todos os sujeitos. Nosso trabalho convida, assim, o leitor e a leitora a relativizarem as leituras que tendem a normatizar o comportamento religioso juvenil, nas quais se busca prescrever o que a experiência religiosa juvenil deve ser. O que buscamos é manter a atenção para a multiplicidade de formas que a experiência religiosa juvenil pode assumir.

Além disso, buscamos demonstrar algumas conexões entre vivências religiosas e itinerários formativos. Não foi nosso intuito demostrar as influências de A sobre B, ou seja, o quanto a pertença religiosa determina o fluxo das experiências universitárias e vice-versa. Respostas a essa questão demandariam outro tipo de estudo e nossos dados não permitem estabelecer essas 
relações causais. Mas podemos, no entanto, indicar alguns nexos que mostram particularidades no que diz respeito à formação de professores.

Ao longo do artigo demonstramos, por exemplo, que os alunos das licenciaturas da UFPR mostram-se, de modo geral, mais ativos em suas comunidades de fé, apresentando índices mais expressivos de participação rotineira nas atividades religiosas. Além disso, observarmos uma distribuição de alunos entre os diferentes grupos religiosos menos concentrada nas licenciaturas do que nos bacharelados, refletindo a adesão dos e das discentes da licenciatura a um conjunto mais diversificado de religiões, bem como maior abertura para conjugar duas ou mais religiões, embora a ampla maioria se engaje de modo exclusivo a uma única denominação e haja o predomínio da matriz cristã. Outro aspecto que nos chamou a atenção é que, dentre os estudantes dos cursos de formação de professores, há uma forte percepção de que a frequência às atividades religiosas é pouco alterada com a rotina universitária, mantendo-se nos níveis prévios à entrada na UFPR. Por outro lado, quando há diminuição na frequência, a falta de tempo e conflitos com o conhecimento veiculado pela universidade se configuram como justificativas de igual peso para esses estudantes, diferente do que ocorre com os colegas dos bacharelados. No aumento de frequência aos grupos religiosos, observamos que a religião é apontada como responsável por oferecer acolhimento em momentos de incertezas durante a graduação.

O quadro que esboçamos acima nos desafia a pensar sobre como a religião está, indelevelmente, inscrita na experiência de formação docente, de modo mais acentuado do que ocorre na formação dos bacharéis. O que encontramos no grupo dos licenciados é um convívio maior dos alunos com colegas de diferentes crenças - algo que pode influenciar na própria experimentação desses alunos em grupos diferentes do seu, ainda que de uma maneira não muito frequente, o que lhes faculta uma experiência de diversidade e de alteridade que é fundamental para seu exercício profissional. Mas nossos dados também permitem inferir que a adesão desses estudantes a uma gramática secular, igualmente fundamental para o desempenho como futuros professores, envolve nesse grupo desafios específicos.

Temos ainda um longo e desafiador caminho a percorrer na análise dos dados deste levantamento de modo a aprofundar a reflexão de como o conhecimento científico universitário se articula com a vivência religiosa dos alunos. Esperamos, com este artigo, ter aberto um campo de explorações, lançando o convite para olharmos com mais atenção para as relações entre o universo religioso e o universo acadêmico universitário brasileiro, bem como as relações, imbricações ou intersecções entre religião e espaço público tão caras para a defesa da laicidade. 


\section{REFERÊNCIAS}

ALMEIDA, Ronaldo de; MONTERO, Paula. Trânsito religioso no Brasil. São Paulo Perspec., São Paulo, v. 15, n. 3, p. 92-100, 2001.

ASTIN, Alexander et al. Cultivating the spirit - how college can enhance students 'inner lives. San Francisco, CA: Jossey-Bass, 2011.

BALLOUSIER, Anna. Cara típica do evangélico brasileiro é feminina e negra, aponta Datafolha. Folha de S. Paulo. [on line]. 13 jan. 2020. Disponível em: https://www1. folha.uol.com.br/poder/2020/01/cara-tipica-do-evangelico-brasileiro-e--feminina-enegra-aponta-datafolha.shtml. Acesso em: 05 mar. 2020.

BERGER, Peter. A dessecularização do mundo: uma visão global. Religião e Sociedade, Rio de Janeiro, v. 21, n. 1, p. 09-23, 2000.

BERGER, Peter. O dossel sagrado: elementos para uma teoria sociológica da religião. 8. reimpressão. São Paulo: Paulus, 2012.

CAMURÇA, Marcelo. Religiosidade moderna e esclarecida entre os universitários das Ciências Sociais de Juiz de Fora - MG. Debates do NER, Porto Alegre, v. 2, n. 2, p. 37-64, 2001.

CAMURÇA, Marcelo. Os “sem religião" no Brasil: juventude, periferia, indiferentismo religioso e trânsito entre religiões institucionalizadas. Estudos de Religião, São Bernardo do Campo, v. 31, n. 3, p. 55-70, 2017.

CARDOSO, Alexandre; PÉREZ, Léa Freitas; OLIVEIRA, Luciana. Quem mora ao lado? O pecado ou a virtude?! Um estudo comparativo sobre adesão religiosa e política entre estudantes de Ciências Sociais e de Comunicação da FAFICH/UFMG. Debates do NER, Porto Alegre, v. 2, n. 2, p. 65-102, 2001.

CASANOVA, José. Public religions in the modern world. Chicago; Londres: The University of Chicago Press, 1994.

CUNHA, Luiz Antônio. Hegemonia e confronto na produção da segunda LDB: o ensino religioso nas escolas públicas. Pro-Posições, Campinas, v. 25, n. 1, p. 141-159, 2014.

CUNHA, Magali do Nascimento. A Explosão Gospel. Um olhar das ciências humanas sobre o cenário evangélico no Brasil. Rio de Janeiro: Mauad, 2007.

CURY, Carlos Roberto. Ensino religioso na escola pública: retorno de uma polêmica recorrente. Revista Brasileira de Educação, Rio de Janeiro, n. 27, p. 183-191, 2004.

DAVIE, Grace. Believing without Belonging: Is This the Future of Religion in Britain? Social Compass, Louvain, v. 37, n. 4, p. 455-469, 1990.

DORVILLÉ, Luis Fernando; SELLES, Sandra. Conflitos e tensões entre ciência e religião nas visões de mundo de alunos evangélicos de uma licenciatura em ciências. 
En: CONGRESO INTERNACIONAL SOBRE INVESTIGACIÓN EN DIDÁCTICA DE LAS CIENCIAS, 8., 2009, Barcelona. Enseñanza de las Ciencias, Número Extra, Barcelona, p. 2750-2754, 2009

FRESTON, Paul. Protestantes e politica no Brasil: da constituinte ao impeachment. 1993. Tese (Doutorado em Sociologia) — Universidade Estadual de Campinas, Campinas, 1993.

FULLER, Robert. Spiritual, but Not Religious: Understanding Unchurched America. New York: Oxford University Press, 2001.

GAIGER, Luiz Inacio; LOCKS, Eliane; SILVA, Cleonice. Uma visão preliminar dos estudantes da UNISINOS. Debates do NER, Porto Alegre, v. 2, n. 2, p. 65-102, 2001.

HERVIEU-LÉGER, Danièle. Le pèlerin et le converti, la religion en mouvement. Paris: Flammarion, 1999.

IBGE. Censo demográfico 2010. Características gerais da população, religião e pessoas com deficiência. Rio de Janeiro: IBGE, 2010.

JUNGBLUT, Airton. A religião entre os estudantes de Ciências Sociais hoje: declínio do ateísmo ou despolarização de posicionamentos? Debates do NER, Porto Alegre, v. 1, n. 2, p. 133-143, 2001.

JUNQUEIRA, Sérgio; TEÓFILO, Debora. Elementos religiosos do universitário. Rever, São Paulo, v. 13, n. 2, p. 149-168, 2013.

KNOBLAUCH, Adriane. Religião, formação docente e socialização de gênero. Educação e Pesquisa, São Paulo, v. 43, n. 3, p. 899-914, 2017.

LEWGOY, Bernardo. Secularismo e Espiritismo nas Ciências Sociais: Discutindo os resultados da UFRGS. Debates do NER, Porto Alegre, v. 2, n. 2, p. 103-116, 2001.

MAFRA, Clara. Censo da religião: um instrumento dispensável ou reciclável? Religião \& Sociedade, Rio de Janeiro, v. 24, n. 2, p. 152-159, 2004.

MALACARNE, Vilmar. Ciência e Religião na fala dos professores de Física, Química e Biologia. Cadernos de Educação, Pelotas, n. 33, p. 81-101, 2009.

MARIANO, Ricardo. Neopentecostalismo: sociologia do novo pentecostalismo no Brasil. São Paulo: Loyola, 1999.

MARIZ, Cecília. Secularização e dessecularização: comentários a um texto de Peter Berger. Religião \& Sociedade, Rio de Janeiro, v. 21, n. 1, p. 25-39, 2000.

MENDONÇA, Antonio Gouvêa; VELASQUES FILHO, Prócoro. Introdução ao Protestantismo. 2 ed. São Paulo: Loyola, 2002.

MENEZES, Renata de Castro. Religiões, números e disputas sociais. Comunicações do ISER, Rio de Janeiro, n. 69, p. 60-70, 2014. 
MEZZOMO, Frank; PÁTARO, Cristina; ROSA, Daiana. Religião e política: aproximações e permeabilização a partir do olhar de jovens universitários. Fragmentos de Cultura, Goiânia, v. 27, n. 1, p. 44-57, 2017a.

MEZZOMO, Frank; PÁTARO, Cristina; ROSA, Daiana. "Ter fé é mais importante que ter crenças e religião": compreensões de jovens universitários sem religião. LINKSCIENCEPLACE - Revista Cientifica Interdisciplinar, Campos dos Goytacazes, v. 4, n. 4, p. 72-86, 2017 b.

MORI, Vanessa; SILVA, Claudia N. da. A religiosidade dos estudantes de uma universidade pública: considerações a partir do curso de Serviço Social. PLURA, Revista de Estudos de Religião, Juiz de Fora, v. 7, n. 1, p. 439-457, 2016.

NOVAES, Regina. Religião e política: sincretismos entre alunos de Ciências Sociais. Comunicações do ISER, Rio de Janeiro, n. 45, p. 64-74, 1994.

NOVAES, Regina. Os jovens 'sem religião': ventos secularizantes, 'espírito de época' e novos sincretismos. Notas preliminares. Estudos Avançados, São Paulo, v. 18, n. 52, p. 321-330, 2004.

NOVAES, Regina. Em nome da Diversidade. Notas sobre novas modulações nas relações entre religiosidade e laicidade. Comunicações do ISER, Rio de Janeiro, n. 69, p. 131-145, 2014.

PEREIRA, Karine; HOLANDA, Adriano. Espiritualidade e religiosidade para estudantes de Psicologia: Ambivalências e expressões do vivido. Rev. Pistis Prax., Teol. Pastor., Curitiba, v. 8, n. 2, p. 385-413, 2016.

PIERUCCI, Antônio Flávio. Reencantamento e dessecularização: A propósito do autoengano em sociologia da religião. Novos Estudos CEBRAP, São Paulo, n. 49, p. 99-117, 1997.

PINHEIRO, Marcos; SANTOS, Elton. Ensino Superior e experiência religiosa: o perfil religioso dos estudantes de Educação Física. Revista Tecer, Belo Horizonte, v. 10, n. 19, p. 101- 111, 2017.

PITTA, Marcelo et al. Pesquisa Perfil da Juventude na PUC-Rio: relatório analítico. Rio de Janeiro: CERIS, 2007.

PRANDI, Reginaldo. As religiões afro-brasileiras em ascensão e declínio. In: TEIXEIRA, Faustino; MENEZES, Renata (org.). Religiões em movimento - o Censo de 2010. Petrópolis: Vozes, 2013. p. 203-218.

SANCHIS, Pierre. Cultura brasileira e religião... Passado e atualidade. Cadernos CERU, São Paulo, v. 19, n. 2, p. 71-92, 2008.

SCHELIGA, Eva; KNOBLAUCH, Adriane; BELLOTTI, Karina. Diversidade religiosa na UFPR: oportunidades, limites e desafios de uma pesquisa sobre religião entre 
universitários. IX SEMINÁRIO NACIONAL RELIGIÃO E SOCIEDADE: O ESPAÇO DO SAGRADO NO SÉCULO XXI. 2018, Curitiba. Anais [...]. Curitiba: Universidade Federal do Paraná, Núcleo de pesquisa em religião, 2018. v. 01. p. 65-67.

SIMÕES, Pedro. Religião e Política entre alunos de Serviço Social (UFRJ). Religião \& Sociedade, Rio de Janeiro, v. 27, n. 1, p. 175-192, 2007.

STEIL, Carlos A; ALVES, Daniel; HERRERA, Sonia R. Religião e Política entre alunos de Ciências Sociais: a definição de um perfil. Debates do NER, Porto Alegre, v. 2, n. 2, p. 09-35, 2001.

SWATOWISKI, Claudia; SILVA, Dayane; ALVARENGA, Otávio. Religião no contexto universitário: uma pesquisa entre estudantes de Ciências Sociais e Psicologia da UFU. Interseções: Revista de Estudos Interdisciplinares, Rio de Janeiro, v. 20, n. 2, p. 388411, 2018.

TEIXEIRA, Faustino. Campo religioso em transformação. Comunicações do ISER, Rio de Janeiro, n. 69, p. 34-45, 2014.

TEIXEIRA, Faustino; MENEZES, Renata (org.). Religiões em movimento - o Censo de 2010. Petrópolis: Vozes, 2013.

TEIXEIRA, Pedro; ANDRADE, Marcelo. Entre as crenças pessoais e a formação acadêmica: como professores de biologia que professam fé religiosa ensinam evolução? Ciência e Educação, Bauru, v. 20, n. 2, p. 297-313, 2014.

VALENTE, Gabriela. A religiosidade na prática docente. Revista Brasileira de Estudos pedagógicos RBEP-INEP, Brasília, v. 98, n. 248, p. 198-211, 2017.

Texto recebido em 06/04/2020.

Texto aprovado em 14/09/2020. 